\title{
12. AS ARBITRÁRIAS INTERNAÇÕES DO DR. SIMÃO BACAMARTE NA “CASA VERDE” EM COTEJO COM O ACESSO À JUSTIÇA E AO DEVIDO PROCESSO LEGAL - REAFIRMAÇÃO DAS GARANTIAS CONSTITUCIONAIS
}

\author{
Rogério Moreira Lins Pastl ${ }^{1}$
}

\begin{abstract}
Resumo: O Alienista de Machado de Assis é um clássico de nossa literatura que trás uma discussão acerca de quem e de quais comportamentos são normais em nossa sociedade. Na obra, o consagrado autor tenta compreender, através de suas teorias, os distúrbios psicológicos dos moradores da cidade de Itaguaí, através da análise da conduta social e interrelacional das pessoas daquela sociedade. O conto machadista trás em seu bojo a análise do comportamento das pessoas, os quais passam por verdadeiro julgamento pelo protagonista, o qual decide se os mesmos são ou não compatíveis para convívio em sociedade, a ponto de internar compulsoriamente aquelas pessoas com enfermidades mentais. Este trabalho destina-se, assim, a fazer algumas considerações acerca dos princípios do acesso à justiça e do devido processo legal, tendo como pano de fundo o enredo e ambientação da obra "O Alienista", sublinhando que um dos desafios que o texto impõe ao leitor diz respeito à forma como estas pessoas eram "internadas ou hospedadas na Casa Verde", trazendo, ainda, à realidade das internações involuntárias dos usuários de entorpecentes.
\end{abstract}

Palavras-chave: princípios processuais; acesso à justiça e devido processo legal.

Abstract: The "Alienista" by Machado de Assis is a classic of our literature that brings a discussion about from who and what behaviors are normal in our society. In the book, the renowned author tries to understand, through his theories, psychological disorders of the residents of the city of Itaguaí, through the analysis of social behavior and interrelation of people in that society. The tale machadista brings inside the analysis of people's behavior, which undergo a real trial by the protagonist, which decides whether or not they are compatible for life in society, to the point of force the hospitalization of those with mental illness. This work is designed, therefore, to make some comments on the principles of access to justice and due process of law, having as backdrop the plot and the setting of the book "O Alienista", stressing that one of the challenges that the text imposes to the reader is with respect to how these people were "hospitalized or hosted at Casa Verde", bringing, also, the reality of involuntary hospitalization of drug users.

Keywords: procedural principles, access to justice and due process of law.

$1 \quad$ Formado em Ciências Jurídicas e Sociais pela UFRGS. Mestre em Direito pela UNISINOS. Membro da Comissão Especial de Legislação e Direito Desportivo da OAB/RS. Professor de Teoria Geral do Processo e de Direito Processual Civil da Faculdade CESUCA. Professor do Curso de Pós-Graduação em Direito do Trabalho e Previdenciário da UNIRITTER. Coordenador Conjunto do Núcleo de Direito Desportivo da Escola Superior da Magistratura da AJURIS. Advogado. 


\section{Considerações iniciais}

Discute-se se as medidas adotadas pelo Dr. Simão Bacamarte eram corretas ou não em "O Alienista". Teria o renomado médico poderes e conhecimento para decidir que eram louco ou normal?

Deste questionamento inicial, surgem algumas interrogações acerca de tais internações: as mesmas poderiam ser tidas como legais, à luz de nosso sistema processual? O Poder Judiciário foi alguma vez provocado a manifestar-se acerca das internações? 0 devido processo legal restou observado? Garantia-se a população alvo do Dr. Simão Bacamarte o acesso à justiça, como garantia constitucional?

A obra literária tem suporte no pressuposto de que o Dr. Simão Bacamarte, após conseguir fama e respeito pela carreira médica desenvolvida na Europa e no Brasil, resolve estabelecer-se profissionalmente em sua cidade, onde passaria, então, a desenvolver uma série de estudos psiquiátricos.

Isso leva-o a construir um manicômio e a determinar a internação de diversas pessoas. Esta iniciativa, inicialmente, goza de certo apoio popular, mas, com o passar do tempo e com os excessos cometidos pelo protagonista, logo gera-se uma revolta popular, no sentido de contestar as teorias e práticas do Dr. Bacamarte.

O ponto fulcral de análise deste trabalho é, justamente, estabelecer, a partir do texto literário, como o princípio constitucional do devido processo legal serve de garantia aos cidadãos e, ainda, para estabelecer os relevantes contornos que o acesso à justiça tem em uma sociedade democrática e no Estado de Direito.

As disposições constitucionais acerca do Poder Judiciário, que criam, organizam e atribuem competências a seus magistrados no mister de prestar a jurisdição, asseguram garantias aos julgadores (p. ex.: vitaliciedade, inamovibilidade, irredutibilidade de 
vencimentos) e fixam princípios processuais aos litigantes, dentre os quais merece o devido destaque o acesso à justiça e o devido processo legal (due process of law).

A premissa inicial de nossa análise tem como base a situação a que as pessoas internadas foram submetidas aos experimentos do Dr. Bacamarte. Analisando-se esta questão pelo prisma do processo judicial, resta claro que os "internos" teriam a sua disposição a tutela e medidas judiciais a fim de se verem livres das "arbitrariedades" perpetradas pelo psiquiatra de Itaguaí. Nesta senda, a garantia do acesso à justiça seria uma forma de exercer a defesa dos direitos violados, em especial a liberdade.

\section{Do acesso à justiça e do devido processo legal}

Algumas palavras devemos traçar acerca do acesso à justiça. Tem-se que acesso à justiça representa uma noção muito mais ampla do que a mera possibilidade do cidadão submeter uma questão controvertida, um conflito de interesses ao Poder Judiciário. Nosso direito positivo entendeu por bem inserir no inciso XXXV do art. 5: da Constituição Federal a obrigação do Estado em desenvolver seu papel de poder/dever no sentido de solucionar os conflitos e a busca da paz na sociedade.

A noção de acesso à justiça e sua efetivação decorre não só da eliminação de entraves econômicos e/ou financeiros, como, por exemplo, a falta de condições do litigante em fazer frente ao pagamento de custas judiciais - assistência judiciária gratuita -, mas também pela possibilidade do Estado prover assistência no que diga respeito à disponibilização de advogado (defensor público, defensor dativo) para patrocinar demanda que diga respeito aos interesses do cidadão que não tenha condições de contratar advogado particular.

Esta ideia central de acesso à justiça não representa apenas o ingresso em juízo (erradicação dos entraves econômicos e financeiros), mas a própria efetivação de toda a oferta de princípios e garantias constitucionais.

Neste contexto, temos que o acesso à justiça implica na universalização e na pronta disposição da jurisdição, a ser alcançada pelo processo judicial, que terá como missão a produção, ao final, de uma decisão que não apenas solucione o caso concreto, mas seja efetivo no sentido de ser célere e que preserve um fim útil e justo em suas decisões. 
O professor Ovídio Araújo Baptista da Silva expõe que direito de acesso à justiça deve ser conjugado ao direito de ampla defesa, ao devido processo legal (inciso LIV do art. 5‥ da CF) e ao contraditório (inciso LV do art. 5‥ da CF), fechando, assim, o que refere ser o ciclo das garantias processuais.

As partes quando estão em juízo buscam receber a prestação jurisdicional, mediante a correta escolha do processo judicial que está a sua disposição. Observe-se que resta claro que o Estado, na divisão de suas atividades, deve dar a cada um o que é seu, segundo os imperativos da ordem jurídica. O reconhecimento destes direitos, no curso de um processo, será feito com amparo nas garantias constitucionais acima citadas. Neste sentido é o pensamento de José Frederico Marques:

\begin{abstract}
Garante-se o processo, e quando se fala em processo, e não em simples procedimento, alude-se, sem dúvida, a formas instrumentais adequadas, a fim de que a prestação jurisdicional, quando entregue pelo Estado, dê a cada um o que é seu, segundo os imperativos da ordem jurídica. E isso envolve a garantia do contraditório, a plenitude do direito de defesa, a isonomia processual e a bilateralidade dos atos procedimentais.
\end{abstract}

O devido processo legal, por sua vez, é, em síntese, processo com procedimento adequado à realização plena do direito e dos valores postos sob análise jurisdicional. 0 processo será o veículo para obtenção do direito material e, como veículo, deverá ser mais ou menos célere, dependendo, evidentemente, da carga que terá de transportar ou que deverá ser analisada quando da prestação da jurisdição.

Necessário, assim, recordar a lição de Robert Alexy²ao referir-se ao processo e procedimento:

Los procedimientos son sistemas de reglas y/o principios para la obtención de un resultado. Si el resultado es logrado respetando las reglas y/o los principios, entonces, desde el aspecto procedimental presenta una característica positiva. Si no es obtenido de esta manera, entonces es defectuoso desde el punto de vista procedimental $y$, por ello, tiene una característica negativa. Este concepto amplio de procedimiento abarca todo lo que cae bajo la fórmula 'realización y asseguramiento de los derechos fundamentales a través de la organización y el procedimiento'. Así,

2 ALEXY, Robert. Teoria de los Derechos Fundamentales. Traduzido por Ernesto Garzón Valdés. Madri: Centro de Estudos Constitucionales, 1993, p. 457-58. 
no obstante notorias diferencias, las normas del derecho contractual y procesal definen igualmente procedimientos: las primeras establecen como puede crearse una obligación contractual; las segundas, cómo puede crearse un fallo. Al mismo tiempo, el concepto amplio de procedimiento y organización deben ser de forma tal que, con suficiente probabilidad y en suficiente medida, el resultado responda a los derechos fundamentales. Puede aquí dejarse de lado la cuestión de saber hasta qué punto es posible crear una conexión tal entre el procedimiento jurídico y sus resultados.

Noticia-se o surgimento do principio do devido processo legal ("due process of law") na Magna Carta Libertatum, de 1215 , na Inglaterra. Sua ideia central esta ligada à garantia da vida, da liberdade e do patrimônio, no sentido de que ninguém possa ser privado ou mesmo ameaçado de perder tais bens da vida senão em virtude do devido processo legal. No conto de Machado de Assis não há submissão das iniciativas do protagonista ao Poder Judiciário, estando, assim, a população de Itaguaí entregue às suas experiências.

Sobre o princípio do devido processo legal, Cintra, Grinover e Dinamarco ensinam que "com essa fórmula, o conjunto de garantias constitucionais que, de um lado, asseguram às partes o exercício de suas faculdades e poderes processuais e, do outro, são indispensáveis ao correto exercício da jurisdição. Garantias que não servem apenas aos interesses das partes, como direitos públicos subjetivos (ou poderes e faculdades processuais) destas, mas que configuram, antes de mais nada, a salvaguarda do próprio processo, objetivamente considerado, como fator legitimante do exercício da jurisdição”3.

Esta garantia traduz-se modernamente no direito que assiste ao litigante de ver aplicado ao processo instaurado o correto procedimento judicial, sem que esteja ao arbítrio do Estado (ou do Juiz de Direito responsável pelo processamento da demanda) a forma casuística ou pontual para solucionar aquela demanda, blindando-se, assim, a solução do caso concreto de nefastos interesses pessoais.

O professor Fredie Didier Jr. traça longo estudo acerca da origem, significação e aplicabilidade do princípio do devido processo legal. Aduz, em apertada síntese, que:

A construção do processo devido é obra eternamente em progresso. 
Essa cláusula geral exerceu e exerce plenamente a sua função de permitir a mobilidade e a abertura do sistema jurídico, como uma "garanzia plastica e flessibile di giustizia nel processo". É por isso que o texto normativo permanece o mesmo há tantos anos, já tendo sido incorporado aos tratados internacionais de direitos humanos e a inúmeras constituições. A generalidade desse texto normativo garantiu a sua longevidade. Trata-se de uma proteção contra a tirania (contra a produção tirânica de normas jurídicas, em nível legislativo, administrativo, jurisdicional e privado). As palavras de Winston Churchill sobre a Magna Carta aplicam-se inclusive e principalmente ao devido processo legal: "E quando, nas idades subsequentes, o Estado, dilatado com sua própria autoridade, tentou impor sua tirania sobre os direitos ou liberdades dos súditos, foi a essa doutrina que vezes e vezes se dirigiram apelos, nunca até hoje sem resultados. $^{4}$

Verdadeiramente, o devido processo legal visa a manter o cidadão protegido contra as vilanias do Estado (e porque não dizer que também dos particulares!!), uma vez que em sua mais simples tradução, o princípio implica em trazer normas processuais e procedimentais previamente estabelecidas para que as partes saibam como deverão se portar em juízo e quais passos deverão percorrer até final julgamento de sua demanda.

\section{Da internação involuntária e coletiva dos usuários de entorpecentes -} Desnecessidade de provimento jurisdicional

A temática da citada obra literária apresenta-se muito atual, não possuindo apenas apelo jurídico-processual. Há clara correlação com as medidas legislativas e judiciais que nossa sociedade vem adotando em face dos consumidores de entorpecentes, as chamadas internações compulsórias e involuntárias.

A imprensa brasileira vem noticiando casos em que viciados em entorpecentes são internados a revelia de sua vontade, face à miserabilidade de suas condições. Neste sentido, observe-se recente notícia publicada no jornal Correio Braziliense:

Segundo a Secretaria de Estado de Saúde de São Paulo, a internação compulsória do usuário T.F.L. foi determinada pela Justiça após constatar que ele, em função do seu grau de intoxicação e de confusão mental, apresentava risco para si mesmo e para outros. T.F.L. relatou aos médicos não saber onde está a família e que usa

$4 \quad$ Fredie Didier Jr.. Curso de Direito Processual Civil - v.1 (2013) - 15a edição: Revista, ampliada e atualizada (2013)., p. 48 e 49. 
"crack, álcool, solvente e cocaína diariamente", diz a nota divulgada pela secretaria.

O jovem de 25 anos de idade, que vivia nas ruas há 15 anos, foi acolhido na região da Nova Luz por voluntários da Missão Belém, grupo católico que presta atendimento a usuários de drogas no centro de São Paulo. Após a avaliação no Cratod e com a decisão judicial, o dependente foi encaminhado para tratamento no Hospital Lacan, em São Bernardo do Campo, Grande São Paulo.

A internação compulsória pode ser adotada em casos que o dependente perdeu os vínculos com os parentes e está em situação de risco. A involuntária ocorre depois de um pedido da família, mediante decisão da Justiça. Desde janeiro, o Cratod recebeu 28,2 mil ligações, fez 4 mil atendimentos e 906 internações, sendo 830 voluntárias. ${ }^{5}$

Observe-se do relato exposto na reportagem, que a internação compulsória do usuário de entorpecentes ocorreu por seu alto grau de intoxicação, pelo risco que o mesmo representava a si mesmo e aos outros, tudo sendo levado ao Juiz de Direito que a determinou. Assiste ao paciente, o direito à defesa e de manifestar-se nas fases processuais que se seguirão no processo em restou determinada sua internação.

Ainda em relação a este assunto, tramita na Câmara dos Deputados em Brasília, projeto de lei que trata da nova legislação antidrogas. O Projeto de Lei no 7663/2010 "autoriza que o dependente químico seja internado para tratamento sem que ele ou o juiz autorize, por intermédio da chamada internação compulsória". O PL adota uma política pública a ser adotada em todo território nacional.

A internação contra a vontade do paciente já consta da Lei 10.216/2001, sendo tratada de maneira individual e conforme as condições do paciente. ${ }^{6}$ primeira-internacao-compulsoria-de-usuario-de-drogas.shtml, acesso em maio de 2013.

Art. 6o da Lei 10216/01: A internação psiquiátrica somente será realizada mediante laudo médico circunstanciado que caracterize os seus motivos.

Parágrafo único. São considerados os seguintes tipos de internação psiquiátrica:

I - internação voluntária: aquela que se dá com o consentimento do usuário;

II - internação involuntária: aquela que se dá sem o consentimento do usuário e a pedido de terceiro;

e

III - internação compulsória: aquela determinada pela Justiça. 
A novidade em relação às internações é que "agora é que o procedimento seja adotado não caso a caso, mas como uma política de saúde pública - o que vem causando polêmica" ${ }^{7}$, como referido pelo articulista Luiz Loccoman.

De fato, o Projeto de Lei no. 7663/2010 visa a regular do Sistema Nacional de Políticas sobre Drogas e dispõe sobre a obrigatoriedade da classificação das drogas, entre outras providências. No rol destas providências, o aludido projeto de lei ratifica a figura da internação involuntária, aquela que se dá sem o consentimento do usuário e a pedido de terceiro, conforme artigo 23-A, II, do PL 7663/2010. Note-se que nesta seara, que as internações serão tratadas como um problema de saúde pública, em que todos os consumidores de drogas poderão, numa só levada, serem internados.

A matéria que envolve o elevado uso de entorpecentes em nossa sociedade, não se limita à esfera legal. Não obstante a possibilidade de se efetuar a internação involuntária individual pela legislação vigente e que o referido projeto de lei venha a aprovar estas internações em caráter coletivo, insta frisar que, pela delicadeza do assunto, necessário que sejam realizados esforços multidisciplinares para buscar uma solução ao impasse.

Neste sentir, serve o exemplo da prática adotada pelo Estado de São Paulo ao desenvolver ações para internar consumidores de tóxico e que estejam em sério estado de risco. Tais ações são desenvolvidas de forma multidisciplinar envolvendo as mais diversas especialidades profissionais (médicas, jurídicas, etc). ${ }^{8}$

Observe-se que a internação involuntária trata da submissão de pessoa a tratamento médico, sem que manifeste esta intenção, sem que um familiar ou responsável venha a anuir com a internação. Dessa maneira, a internação involuntária decorrerá de pedido de terceiro e de avaliação médica que entenda por sua necessidade, individualmente.

$7 \quad$ Disponível $\quad$ em http://www2.uol.com.br/vivermente/artigos/a_polemica_da_internacao_compulsoria.html, acesso em maio de 2013.

8 "Um ano após o início da operação na cracolândia, o governo do Estado de São Paulo vai fazer um "mutirão" para internações involuntárias de dependentes químicos que ficam nas ruas do centro da capital. A permissão de recolhimento será dada por um parente. A ideia é lançar o programa em dez dias, com apoio de psiquiatras, juízes, promotores e advogados." in http://www.estadao.com.br/noticias/impresso,estado-quermutirao-para-internacao--involuntaria-de-viciados-na-cracolandia-,980434,0.htm . 
Observe-se que a solução apontada pelo PL implica na ausência da anuência da pessoa a ser internada, de um familiar e mesmo do Poder Judiciário, ficando a internação a critério de um "terceiro" e de um parecer médico que indique sua necessidade.

A preocupação em torno do assunto, uma vez alijada a participação do Poder Judiciário, é de que medidas dessa natureza sirvam de embasamento para uma política higienista junto às comunidades usuárias de drogas ${ }^{9}$.

Resta-nos, assim, assistir como o Estado, se for o caso, tratará as internações involuntárias em massa, situação esta que, em nenhum hipótese, poderá representar ações como as perpetradas pelo Dr. Simão Bacamarte na cidade de Itaguaí ou mesmo como mote para o desenvolvimento de políticas sociais exterminatórias.

\section{Conclusão}

A par das discussões médicas que revestem o tema da internação involuntária, a qual, ao que parece, ainda está longe de ser definitivamente concluida, deve ser dito que o simples fato de se cogitar que o Poder Judiciário fique alijado de se manifestar acerca das internações pelo uso contínuo e desmedido de entorpecentes, causa na sociedade um sentimento de que estas medidas possam ser arbitrárias e que o cenário proposto por Machado de Assis possa ser reprisado nos grandes centros urbanos, onde a utilização das drogas atinge níveis insuportáveis.

A sociedade não pode permitir que o fato de se legalizar a internação involuntária (individual ou coletiva, caso o PL venha a ser aprovado como ferramenta de política pública) represente violação às garantias individuais expostas na Carta Magna. Esta possibilidade não pode derrogar o acesso à justiça, a um Juiz imparcial, ao contraditório e à ampla defesa. Reforça-se a idéia da garantia do devido processo legal, como corolário lógico do desenvolvimento dos atos processuais.

\section{REFERÊNCIAS BIBLIOGRÁFICAS}

$9 \quad$ Ibidem-reportagem do Estadao.com.br. 
ALEXY, Robert. Teoria de los Derechos Fundamentales. Traduzido por Ernesto Garzón Valdés. Madri: Centro de Estudos Constitucionales, 1993.

MACHADO DE ASSIS, Joaquim Maria. O alienista. Porto Alegre: L\&PM, 2012.

CINTRA, Antônio Carlos de Araújo, GRINOVER, Ada Pellegrini e DINAMARCO, Cândido Rangel Dinamarco. Teoria Geral do Processo. 28a edição. São Paulo : Malheiros, 2012

DIDIER JR, Fredie. Curso de Direito Processual Civil - v.1 - 15a edição: Revista, ampliada e atualizada. Salvador: Jurispodium, 2013.

MARQUES, José Frederico. Manual de Direito Processual Civil, v. 1, 9a. ed. São Paulo: Millenium, 2003.

SILVA, Ovídio Araújo Baptista da. Curso de Processo Civil. Processo de Conhecimento. 4. ed. São Paulo: Revista dos Tribunais, 1998. v. 1.

. Da Sentença Liminar à Nulidade da Sentença. Rio de Janeiro: Forense, 2001.

. Jurisdição e Execução na Tradição Romano-Canônica. 2. ed. rev. São Paulo: Revista dos Tribunais, 1998.

THEODORO JR., Humberto. A Garantia Fundamental do Devido Processo Legal e o Exercício do Poder de Cautela no Direito Processual Civil. Revista dos Tribunais, São Paulo, n. 665, p. 11-22, mar. 1991.

TUCCl, Rogério Lauria; TUCCl, José Rogério Cruz e. Constituição de 1988 e processo: regramentos e garantias constitucionais do processo. Saraiva: São Paulo, 1989. 